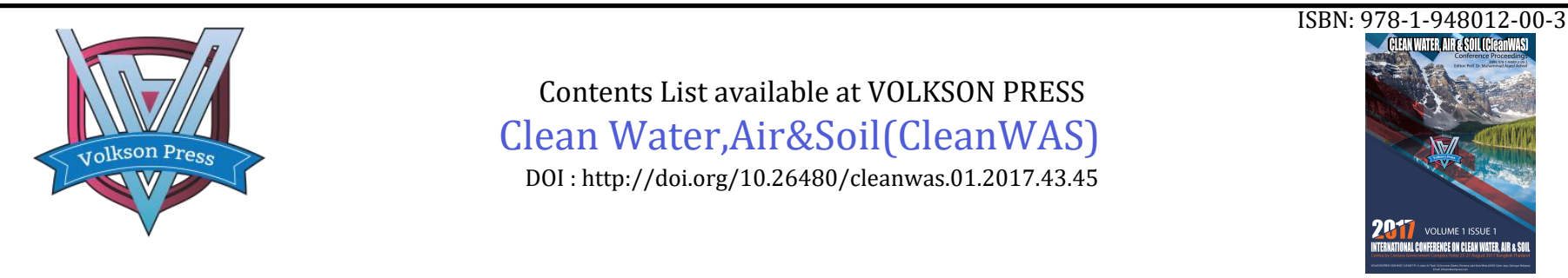

\title{
The Protection Status and Prospect of Great Bustard (Otis tarda) in China
}

\author{
Wu Yiqun and Xu Xiu \\ College of Chemistry and Environment Sciences Weinan Normal University, Weinan, 714099, China \\ *Corresponding Author: wuyq-05@163.com
}

This is an open access article distributed under the Creative Commons Attribution License, which permits unrestricted use, distribution, and reproduction in any medium, provided the original work is properly cited

\section{ARTICLE DETAILS}

\section{Article History:}

Received 02 october 2017 Accepted 06 october 2017 Available online 11 october 2017

\section{Keywords:}

Great Bustard, endangered

factors, conservation biology,

conservation strategies

\section{ABSTRACT}

Great Bustard is a species of protected bird as the first class in China and the endangered species in the world . According to the current data combined with the recent research, in this paper, endangered mechanism and protective issues of Great Bustard were discussed and analyzed. In addition, some suggestions were put forward to provide basic information for the field protection of the species.

\section{Introduction}

Conservation biology is a new comprehensive discipline in biological science field. As a cross subject, conservation biology involves biology, geography, sociology, and decision science discipline,because of its good theoretical basis, conservation biology has developed rapidly, has formed a complete system of scientific theories. In the future development, the key research areas of conservation biology include genetics protection, ethology protection, and ecology conservation.

Great Bustard (Otis tarda) commonly known as wild goose, in taxonomy, it is belong to Gruiformes and Otidae. In China, it is listed in key protected wild animals of the first level. The world union for conservation of nature (IUCN) lists it as the red list of endangered species in 2012 - the low risk (LC) species ${ }^{[1]}$. In recent decades, due to the interference and influence of human activities, the over-exploitation and utilization of wetlands and grasslands has caused the breeding ground of Great Bustard and the habitat degradation of the wintering land.At present, as a result of habitat fragmentation and patch edge effect has survival pose a serious threat to Great Bustard, at the same time, fewer and fewer wild populations of Great Bustard also makes it face the risk of loss of genetic diversity [2]. From 2012 to 2016, the author conducted a field survey on the survival status of the Great Bustard in the area of Great Bustard in the Yellow River Wetland in Shaanxi Province, and published several papers ${ }^{[1,3-6]}$. In order to provide references for bustard species protection data, based on the existing research materials, this paper summarizes Great Bustard's endangered mechanism, and protection status are analyzed and put forward relevant suggestions.

\section{Protection Measures}

Facing the severe situation of Great Bustard's survival, it is urgent to take more effective action for the concerned countries and organizations. In July 1997, the first international Great Bustard protection symposium held in Russia. in December 2009, "the first international symposium on Great Bustard protection and monitoring network" was held in Beijing forestry university, which is strengthen the international cooperation of Great Bustard protection work,and have promoted the exchange of the protection of information and scientific research. Protection of natural populations in the wild state is the best way to protect biodiversity. Through years of efforts, China has set up a multiple Great Bustard nature reserves, such as Tumuji reserve in Inner Mongolia firstly established in order to protect the Great Bustard national nature reserve. At the same time, the cooperative protection of the Great Bustard breeding ground, wintering ground, migration site and stoppage is also achieved, which greatly promoted the research and protection work of Great Bustard.

In China, the work of the Great Bustard artificial feeding began in the middle of the 20th century.Several wildlife treatment stations and Great Bustard breeding centers have been established, bringing a new turning point in the protection and population recovery of Great Bustard. In addition, it also aimed at the artificial breeding of the Great Bustard to carry out technical attack, obtained the valuable experience that raises Great Bustard. In 2001, under the condition of Harbin Zoo achieved in captivity Great Bustard normal fertilization, showed caged Great Bustard has reproductive success in China. By 2008, according to the existing 25 breeding center, 124 Great Bustards were raised, the quantity of Great Bustard were successful breeding breeding, conservation show that exsitu conservation has become an important technical measures to maintain Great Bustard population.Although there has been some progress in the protection of the bustard, there is still a lot of work to be done to further the effective measures to expand the number of wild populations and enhance the survival of the population.

\section{Existing Problem}

\subsection{Regional Economic Development and Protection}

Under the condition of the regional economic development, economic development activities have become more and more in reserves, the breeding and wintering Great Bustard is facing a series of new problems, mainly in agricultural structure changes affect the survival environment of Great Bustard and food source, a legacy of heavy metal pollutants from industrial and agricultural production affected physiological and biochemical indexes of Great Bustard.

In recent years, animal husbandry has been developing rapidly, and grassland grazing has caused an unrecoverable destruction of [7]. Driven by economic interests, the wetland of the Yellow River in Shaanxi Province in large reeds gradually replaced by lotus pool, fish pond, and the development of natural resources has been more than a moderate range, 
such as excavation of lotus and fishponds grid frequent human activities having a direct effect on the survival of Great Bustard.

In addition, in order to the development of regional tourism economy, the construction of "the Yellow Tour Line" has great changes that birds roosting habitat. Noise pollution and traffic increase lead to some sensitive alert birds, especially some endangered birds have to fly to other area, a large number of migratory birds may choose Henan Province and other places of the Yellow River wetland to pause and winter. Therefore, it is still an important question to rationalize the relationship between endangered species and the orderly exploitation of resources.

\subsection{Defective Ex-situ Conservation Work}

At present, the protection work has made some achievements, but did not achieve expected goals, artificial feeding Great Bustard population remained at a low level[8], ex-situ conservation work faces many problems. Great Bustard is ecological indicator species, higher requirements to the external environment condition and artificial breeding conditions, the external environment is likely to be small changes make Great Bustard can not adapt to breeding conditions and produce many excesses, cause adverse effect on the survival of the population ${ }^{[9]}$.

Therefore, how to accurately simulate the field environment and make it better adapt to the artificial raising environment is the urgent problem to be solved in the current relocation protection work. In addition, the breeding technology of bustard chicks is not mature enough, and the success rate of raising chicks is still lower[10]. In breeding farms, Newcastle disease, colibacillus, enteritis and other diseases can cause serious harm to the survival of Great Bustard populations.In 2010, there were 12 spawning eggs in Changchun's Animal and Vegetable Park, and only one of them successfully hatched, and it died from infection. Therefore, it remains to be improved to protect the artificial incubation, artificial breeding technology and disease control in the ex-situ conservation.

\section{Prospect}

\subsection{Strengthen the Habitat Management}

At present, the contradiction between the Great Bustard protection and regional economic development has become prominent contradiction, which requires to face new problems appear constantly, in a timely manner to protect existing research emphasis and strategy makes the corresponding adjustment. (1) expand the research team, accelerate the construction of the Great Bustard protection monitoring network, and formulate feasible protection measures; (2) strengthen the management and construction of Great Bustard reserve, moderate to establish effective mechanism of ecological compensation, on the local planting crops such as wheat, corn, able to provide supplementary food source for Great Bustard residents with certain economic subsidies; (3) the local government should actively guide the local herdsmen looking for a rich way, provide more employment opportunities, changed the cattle before onto to fixedpoint captive to extensive range to fine farming, such not only can reduce the grassland reclamation area, and can promote local economic development, thoroughly change the predatory use of resources; (4) layout of scientific planning road network, reasonably arrange the life and production activities in the protected area; (5) speed up the construction of ambulance stations.

\subsection{Artificial Breeding and Restore Wild Population}

Establish the blood pedigree of animals and strengthen management, avoid inbreeding and prevent population degeneration. The establishment of artificial domestication and breeding of large Great Bustard, expanding the scale of artificial culture, after the wild training, the field release, recovery and enlarging the population of the Great Bustard population.

\subsection{Mechanism of Endangered Species}

Using molecular biology techniques, tissue samples of different sources of Great Bustard population at the molecular level research, analysis of different species and genetic differences between individuals, discuss the law of population evolution, differentiation, and macro aspects (morphological) combined with microscopic aspect (molecular), from the population genetic structure, physiological and biochemical mechanism and the mechanism of the cause of endangered phenomenon to do further research.
Long-term monitoring of population dynamics and habitat of Great Bustard should be carried out. From an international perspective, bilateral and multilateral relations have been established. Through exchanges and cooperation, learn from other countries' successful experience in the protection of Great Bustard, and introduce funds and technologies, increase research input and enhance the overall strength of scientific research.In addition, the research work of Great Bustard resources is carried out jointly with research institutes and universities to expand the research team, and to fully grasp the dynamic data of the Great Bustard population in the whole country.

\subsection{Promote Education and Enhance Protection Awareness}

To improve the environmental protection consciousness of the local farmers and herdsmen, conduct a training program through various means and propaganda education, make people more in-depth understanding of Great Bustard, protect bustard compulsive behavior into conscious action of farmers and herdsmen. At the same time, the local forestry department strengthens legal management, prohibits grazing in the core area of the reserve, effectively enlarging the usable habitat area. Conscientiously implementing laws and regulations on wildlife protection; At the same time, we need to strengthen the patrol, strictly enforce the law, and provide a good and stable habitat for Great Bustard.

\section{Acknowledgments}

This study was funded by the Agricultural Science and Technology Innovation Projects in Shaanxi Province (2015NY158), the Young Star of Technology Plan Projects in Shaanxi Province (2016KJXX-77).

\section{References}

〔 1 〕 Wu, Y. Q., Shen, J., Liu, J. W., Liu, F. Q., Wang, S. \& Xu, X.(2013). Analysis of the Threatening Factors on Wintering Otis tarda in the Yellow River Wetland of Shaanxi Province. Forest Resources Management, 5:91-94

〔 2 〕 Chen T.S., He, B., Cheng, X.H. \& Wang, B.X. (2011). Causes to the Injury of Great Bustard. Shaanxi Forest Science and Technology, 6:51-53 •

〔3 3 Wu, Y.Q. (2012). Investigation on the Wintering Population of Otis tarda in Yellow River Wetland of Shaanxi Province. Journal of Anhui Agricultural Sciences, 40(16): 8926 •

〔4 \ Liu, J.W., Wu, Y.Q. \& Xu, X. (2013). The Assistance and Conservation of Wintering Great Bustard in Shaanxi Province - Sichuan Journal of Zoology, 32(2): 306-307 .

[5] Wu, Y.Q. \& Liu, J.W. (2013) - The Determination of Heavy Metals in Great Bustard's Feathers and Feces · Science Technology and Engineering, 13(33):9913-9915 •

[6] Wu, Y.Q., Liu, Y.F., Xu, X.\& Liu, J.W. (2013). Analysis of Amino Acid Composition in Faeces and Digestive Ability of Great Bustard (Qtis tarda) during Overwintering. AminoAcids \& BioticResources, 35(3):1-3 ·

[7] Cao, D.W., Zhang, J.E., Li, Y.H.\& Li, W.T. (2004). The status and protection measures of Great Bustard resources in the reserve of Tejinhan Mountain · Inner Mongolia Forestry Investigation and Design , 27:48-49

[ 8 ] Tian, X.H.\& Zhang, B.L. (2006). Progress in researches of Great Bustard (Otis tarda) in China and its conservation strategy - Chinese Wildlife, 27(3):32-37 .

[9] Tian, X.H., Zhang, B.L., He, B.X. \& Li, X.M. (2005) · Impacts of captive environment change on Great Bustard's behaviors in breeding season . Chinese Journal of Zoology, 2005, 40(4):55-59 .

( 10 ] Yao, J., Mu, D.J., Liu, C., Lu, X.Q. \& Yao, Q.Y. (2011) · Captive breeding of Great Bustard Otis tarda - Chinese Wildlife , 32(6): 329-331 .

\subsection{Strengthening Exchanges and Cooperation}

\section{About the Authors}


Wu Yiqun: Male, professor of chemistry and environment, Weinan Normal University, doctor of zoology, master Research on avian ecology. E-mail: wuyq-05@163.com
Xu Xiu: Female, lecturer of chemistry and environment, Weinan Normal University. E-mail: 19800784@qq.com

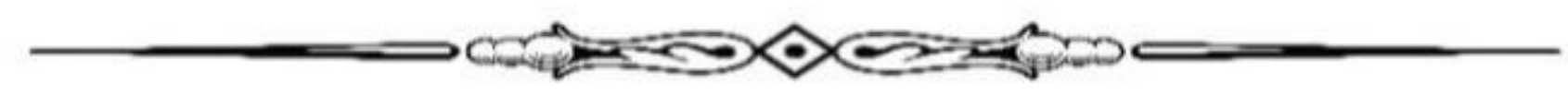

